\title{
Simulating the combined effects of climate and wildfire on streamflow
}

\author{
$\underline{\text { P.M. Feikema }}^{\text {ab }}{ }^{\text {, C.B. Sherwin }}{ }^{\mathrm{b}}$ and P.N.J. Lane ${ }^{\mathrm{b}}$ \\ ${ }^{a}$ Extended Hydrological Prediction, The Bureau of Meteorology, Melbourne, Australia \\ ${ }^{b}$ Department of Forest and Ecosystem Science, The University of Melbourne, Parkville, Australia \\ Email:p.feikema@bom.gov.au
}

\begin{abstract}
In February of 2009, after prolonged periods of hot and dry weather, wildfires spread across part of the state of Victoria, affecting more than $363 \mathrm{~km} 2$ of forests in the Melbourne water supply catchments. This has potential to alter long term water use ( $>100$ years) of the forests and subsequent water yield from these catchments. Climate can have an important role in modifying the effects of fire on streamflow. One of the few ways to examine these is through a process-based modelling study. It is important that the combined effects of climate and wildfire on long term streamflow are included in simulations used by water managers for planning and decision making.

We used a spatially explicit process-based model to explore relationships between climate and wildfire, and examine the combined influence of climate and wildfire on the post-fire streamflow response. Catchments were disaggregated into spatial units at which energy and water balances are simulated. Changes in land cover were expressed as changes in leaf area index (LAI) for the fire sensitive ash-type eucalypt species, and for the more fire-tolerant mixed eucalypt species forests.
\end{abstract}

Catchment water balances were simulated for 100 years after wildfire to include most of the expected changes. We assumed post-fire mortality of vegetation from recent field studies, along with several climate scenarios to examine the response of post-fire catchment streamflow. Effects of climate variability were removed by creating a synthetic climate, with no inter-annual variability, and using this as an input to model.

Under wetter than average conditions, change in post-fire water yield was largely explained by changes in average age of the forest, where ET is largely determined by the conductance and interception of the forest canopy. Under drier conditions, evapotranspiration is largely under the control of soil water content, and so differences in vegetation cover and canopy conductance across catchments are likely to have less effect on evaporative fluxes and consequently on streamflow. Under lower than average rainfall conditions, when water becomes limiting, annual rainfall was the best predictor of post-fire change in water yield. This can result in little or no statistically significant change in post-fire streamflow, even when large areas of a catchment are affected by fire (Bart and Hope, 2010).

Under conditions of low rainfall and low soil water content that are conducive to larger wildfires, any initial increase in post-fire streamflow due to reduced canopy cover may not occur or be detected because a substantial soil water deficit must first be removed before appreciable changes in streamflow will occur. We conclude, therefore, that the likelihood of detecting changes in streamflow after severe wildfire is lower when rainfall is low.

Keywords: $\quad$ process-based modelling, Macaque, forest, wildfire, streamflow 


\section{INTRODUCTION}

Most of the water for the city of Melbourne, Australia, comes from a number of forested catchments to the north-east and east of the city. The amount of precipitation that is evaporated and transpired from these catchments largely depends on age and structure of the forests. Wildfire has the potential to result in changes in vegetation structure and water use, with consequential changes in streamflow into water supply reservoirs (Vertessy et al., 1998).

Under extreme weather conditions in February 2009, a wildfire affected approximately 363 $\mathrm{km}^{2}$ of forests in the Melbourne water supply catchments (Error! Reference source not found.). Approximately $145 \mathrm{~km}^{2}$ of the fire area was severely burnt (fire severity classes 1 and 2), with a considerable part of the fireaffected areas experienced low fire severity (fire severity classes 4 and 5). This has the potential to alter long term water use $(>100$ years) of the forests and subsequent streamflow.

A relationship between age and streamflow for E. regnans was generalised by Kuczera (1987) by the 'Kuczera curve', which predicts a decline in water yield after fire, leads to an average annual water yield reduction of up to $50 \%$ at between 20 to 30 years, which is followed by a gradual recovery in mean annual streamflow to an equilibrium water yield over the following 100-200 years (see Fig. 2 in Vertessy et al., 2001). Watson et al. (2001) revised the Kuczera (1987) relationship based on a study of smaller paired experimental catchments and their revised relationship includes a sharp initial increase in water yield above long term values in the first five years after fire before it declines.

Given the substantial area of eucalypt forest burnt during the 2009 wildfire, there is potential for long term streamflow decline. This study was undertaken to estimate the magnitude of that decline, by incorporating spatial data on forest type, forest age, fire severity and forest mortality into a physicallybased modelling approach that predicts catchment streamflow as it is affected by climate and catchment characteristics. In this study, we examine the relationship between climate and wildfire on long term streamflow, and in particular examine the role climate has in the magnitude of that effect.

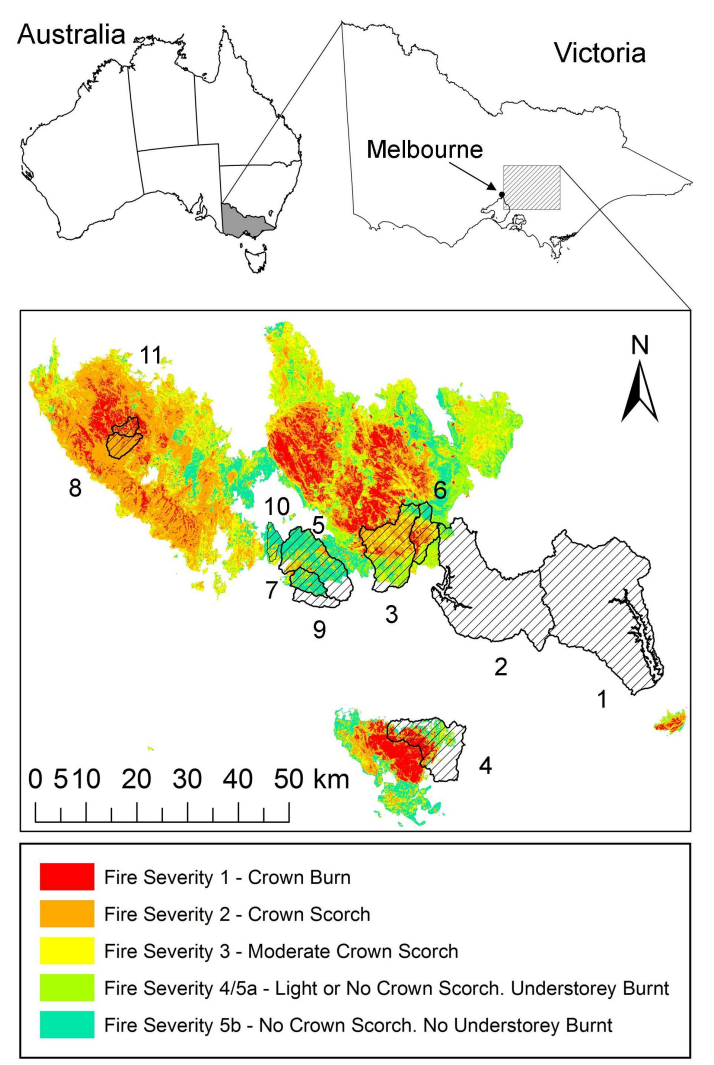

Figure 1. Location of water supply catchments included in this study. Catchments are 1. Thomson, 2. Upper Yarra, 3. O'Shannassy, 4. Tarago, 5. Watts, 6. Armstrong 7. Grace Burn, 8. Wallaby Creek, 9. Coranderrk, 10. Donnelly's Creek 11. Silver Creek. See Table 1 for details. 
Feikema et al., Simulating the combined effects of climate and wildfire on streamflow

Table 1. Catchment details.

\begin{tabular}{llccccccc}
\hline No. & Catchment & Latitude & Longitude & Area $\left(\mathrm{km}^{2}\right)$ & $\begin{array}{l}\text { Long term } \\
\text { average rain }\end{array}$ & $\begin{array}{c}\text { \% affected } \\
\text { by fire }\end{array}$ & $\begin{array}{l}\text { \% affected by } \\
\text { severe fire }^{\mathrm{b}}\end{array}$ & $\begin{array}{c}\text { \% forest } \\
\text { mortality }\end{array}$ \\
\hline 3 & O'Shannassy & -37.68 & 145.81 & 118.9 & 1680 & 93 & 41 & 52 \\
4 & Tarago & -38.02 & 145.94 & 112.9 & 1280 & 52 & 29 & 24 \\
5 & Watts & -37.64 & 145.55 & 101.6 & 1520 & 79 & 8.2 & 6.3 \\
6 & Armstrong Creek & -37.64 & 145.86 & 39.3 & 1620 & 100 & 46 & 44 \\
7 & Grace Burn & -37.66 & 145.57 & 24.9 & 1500 & 97 & 1.6 & 5.6 \\
8 & Wallaby Creek & -37.40 & 145.25 & 22.3 & 1200 & 100 & 100 & 80 \\
10 & Donnelly's Creek & -37.63 & 145.54 & 14.3 & 1420 & 100 & 5.4 & 2.2 \\
11 & Silver Creek & -37.37 & 145.22 & 12.3 & 1170 & 100 & 100 & 67 \\
\hline
\end{tabular}

\section{METHODOLOGY}

\subsection{Study area}

The catchments in this study are part of the Melbourne water supply catchment network (Error! Reference source not found.; Table 1). The catchments are vegetated with wet sclerophyll Eucalyptus forests (known as ash-type eucalypt forest) dominated by Eucalyptus regnans and E. delegatensis. At lower elevation, the forest stands consist largely of E. obliqua and E. cypellocarpa, along with several other Eucalyptus species in mixtures (and known as mixed species forests). Rainfall across the catchments range between 1050 and 1930 mm year ${ }^{-1}$ (Error! Reference source not found.). Soils across the study catchments are generally deep with high hydraulic conductivities (Davis, 2000). These mainly comprise deep gradational friable earths or loams and some higher reaches contain shallow stony earths (DPI \& DSE, 2004).

\subsection{Model and data}

We used Macaque, a physically-based long term water balance model developed by Watson (1999) and summarised by Watson et al. (1999) and Peel et al. (2000). In Macaque, predictions of daily streamflow are sensitive to climate, vegetation water use, the amount of water stored within the soil, and the rate at which this water moves into and out of the soil and into the streams. Movement of water in the unsaturated and saturated zones are simulated.

Catchments are disaggregated into spatial units at which energy and water balances are simulated. Changes in land cover are expressed as changes in leaf area index (LAI) through mechanisms such as LAI control of precipitation, interception storage and the transpiring surface area, as well as LAI control of the amount of radiation intercepted by the canopy and understorey (Watson et al. 1999). Within Macaque, the LAI and leaf conductance are specified to the model as a series of LAI with age and conductance with age relationships for each forest type. Each spatial unit has two soil zones, representing the unsaturated and saturated soil.

An estimate of precipitation at each spatial unit is made using a method that relates total monthly precipitation at many stations to monthly totals (of daily) precipitation at two or three base stations with long and complete record lengths (Peel et al., 2000). An elevation-based lapse rate $\left(-0.005^{\circ} \mathrm{C} \mathrm{m}^{-1}\right)$ was used to calculate maximum and minimum temperatures at each spatial unit relative to a base station using the difference in elevation between the spatial unit and base station.

Spatial vegetation data were obtained from the Victorian Department of Sustainability and Environment (DPI \& DSE, 2004). Vegetation age data for the O'Shannassy catchment are based on a forest type map commissioned by the then Department of Conservation and Natural Resources in a search for Leadbeater's Possum habitat in 1993. Vegetation type and age information for the Wallaby and Silver Creek catchment was derived from hardcopy of a 1:25000 forest type map produced in 1980 and kindly digitised by Melbourne Water.

For the ash-type species (E. regnans, E. nitens, and E. delegatensis), canopy LAI is predicted using the curves developed from experimental data (Watson, 1999, Watson et al., 1999 and Vertessy et al., 2001). For non-ash eucalypts (e.g. E. obliqua) and non-eucalypts, the development of long term LAI is assumed to have constant LAI, following a rapid initial increase from zero in the first 5 to 10 years following disturbance (Peel et al., 2000). 
Model calibration is described by Feikema et al. (2013) with the objective to maximise the coefficient of efficiency (E) described by Nash and Sutcliffe (1970), while reducing the percentage difference in mean, standard deviation and coefficient of variation between the predicted and observed monthly streamflow data.

\subsection{Simulating long term streamflow}

Catchment water balances were simulated for 100 years after wildfire to include most of the expected changes that would occur in post-fire streamflow. To account for uncertainty in the post-fire mortality of vegetation, Feikema et al. (2013) investigated the effect of several scenarios relating vegetation mortality and fire severity. Here we use the most likely mortality scenario (Scenario B in Feikema et al. 2013) along with several future climate scenarios to examine the response of post-fire catchment streamflow.

We removed the effects of climate variability over longer periods by creating a synthetic climate, with no inter-annual variability, and using this as an input to model simulations in a similar way to Watson (1999) and Peel et al. (2000). We took the daily climate series for a year (1988) representative of the long term average, and repeated it for 100 years. Climate data representative of a recent dry period (1997-2008) as well as two years representing the $99 \%$ confidence level for each of the two climate periods were also used in simulations.

\subsection{Data analysis}

Catchment and total annual streamflow was examined in terms of total water yield and percentage change in water yield relative to the no-fire simulations. These were examined in relation to rainfall, and mortality induced changes in forest age and forest type in each catchment.

\section{RESULTS AND DISCUSSION}

\subsection{Catchment response}

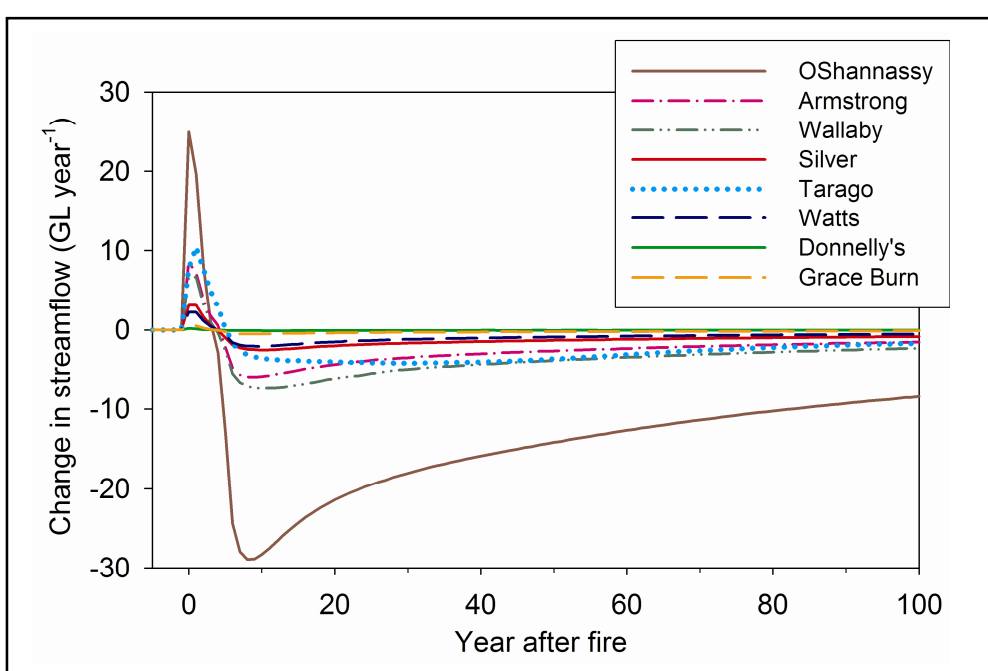

Figure 2. Simulated annual streamflow after the 2009 wildfire.

The wildfire is estimated to lead to the largest reduction in water yield in the O'Shannassy catchment (Figure 3), largely due to the old average forest age, relatively high rainfall, and the highest rate of forest mortality.

Wallaby Creek catchment is estimated to be the second most affected catchment. Although $100 \%$ of the catchment area was affected by fire, rainfall is much lower, and the magnitude of a decline in streamflow will probably be substantially lower. This catchment is at the drier end of the study area, and therefore the relative impact expressed as a percentage of water yield is much larger than that on the O'Shannassy catchment. The large relative impact is not surprising given the average age of the forest (123 years) and the relatively high proportions of the catchment with ash-type forest severely burnt $(32 \%)$.

\subsection{Relative effect of climate}

To illustrate the relative effects of climate, we only present simulations for the two most affected catchments - O'Shannassy and Wallaby Creek. The influence of rainfall on total post-fire streamflow for these two catchments is shown in Figure 3, where the change in streamflow over time is shown for four synthetic climate sequences (wet $=184 \%$ rainfall, average $=100 \%$ rainfall, dry $=84 \%$ rainfall, very dry $55 \%$ rainfall). 


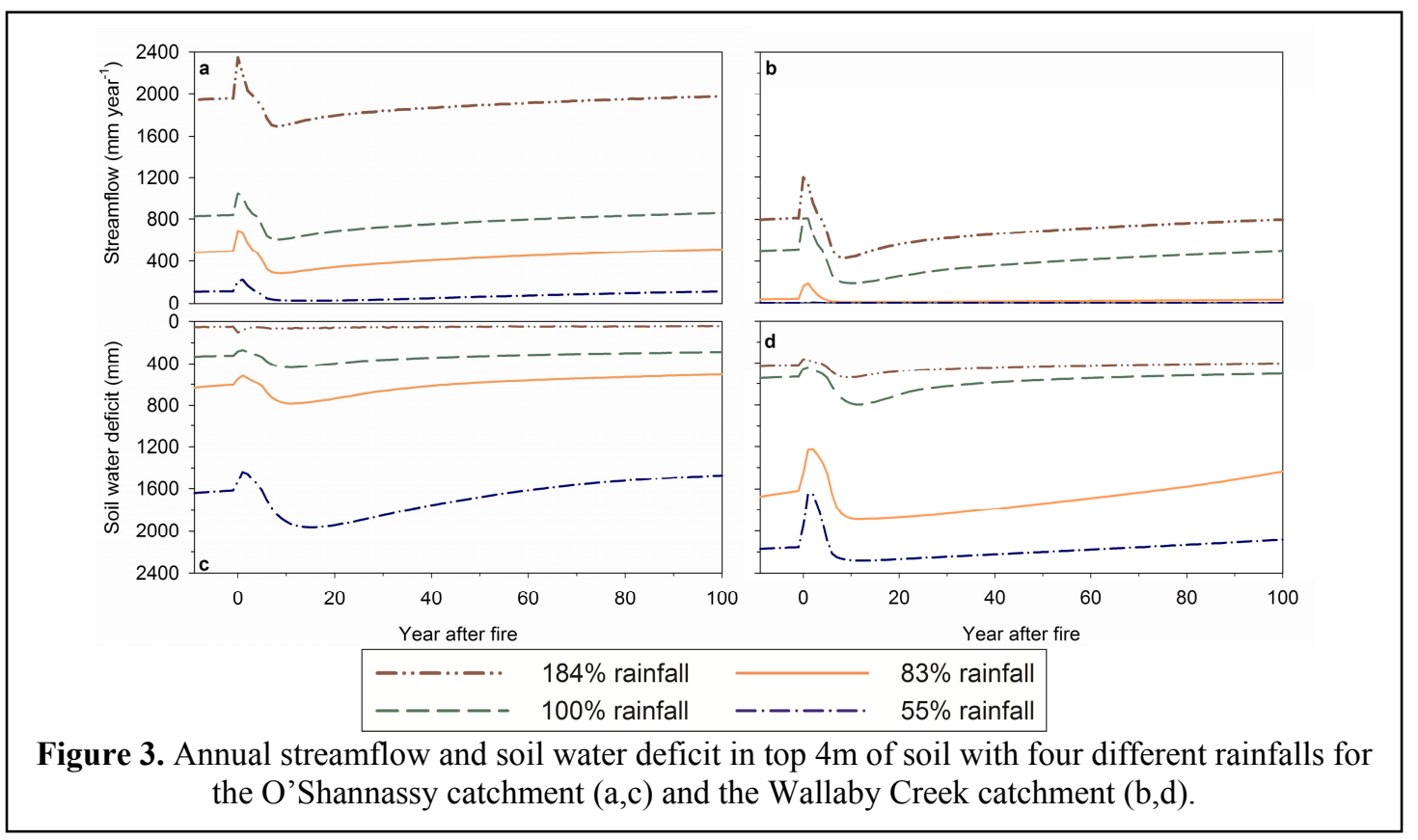

For both catchments, as rainfall decreases, the simulated magnitude in initial peak and longer term reduction in streamflow also decreases (Figure 4). Conversely, as rainfall decreases, the magnitude of the post-fire change in soil moisture content increases (Figure 4). This is because, under below average rainfall conditions, the soil is drier, and the soil water deficit is greater than would normally exist. A reduction in ET (particularly transpiration and rainfall interception by the canopy) resulting from forest mortality leads to relatively more water entering the soil. The change in soil water content therefore increases after an event such as wildfire and forest mortality. The greater than normal soil water deficit must first be removed before appreciable increases in post-fire streamflow can occur.

For the O'Shannassy catchment, under long term average rainfall $(100 \%$ rainfall $)$ the change (maximum increase) in post-fire streamflow is estimated to be approximately $210 \mathrm{~mm}$, with an eventual maximum reduction in streamflow of approximately $230 \mathrm{~mm}$. The same predictions for the Wallaby Creek catchment were larger in magnitude (300 and $310 \mathrm{~mm}$ respectively) due mainly to higher canopy mortality $(80 \%)$ than the O'Shannassy catchment (52\%).

Under conditions corresponding to the recent dry period between 1997 and 2009 (83\% rainfall), the magnitude of peak and trough in streamflow was predicted to be lower, with an increase of $\sim 180$ $\mathrm{mm}$ in post-fire streamflow followed by a decrease of $\sim 190 \mathrm{~mm}$. However, this time, for the Wallaby Creek catchment, post-fire increase $(\sim 140 \mathrm{~mm})$ and subsequent decrease $(\sim 30 \mathrm{~mm})$ were smaller. This can be explained by the substantially larger soil water deficit in the Wallaby Creek catchment $(\sim 390 \mathrm{~mm})$ when compared to the O'Shannassy catchment $(\sim 90$ $\mathrm{mm}$ ). With average or above-average rainfall, the soil water deficit is sufficiently low so that the change in streamflow is largely influenced by the change in forest structure (age, type, and mortality). With below average rainfall, large soil

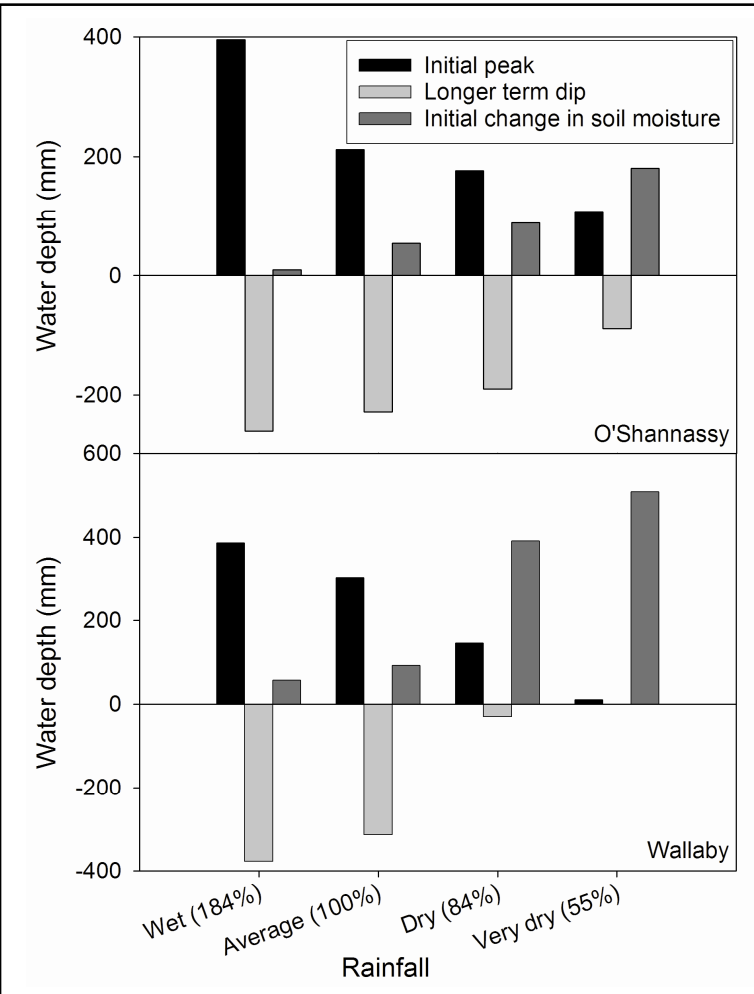

Figure 4. Magnitude of the initial peak in streamflow, initial change in soil moisture, and longer term decrease in streamflow for the O'Shannasy and Wallaby Creek catchments. 
water deficits become the dominant process in influencing the post-fire streamflow response. Under extremely dry conditions (55\% rainfall), when soil water deficits are at their largest, increases and subsequent decreases in post-fire streamflow are lowest (Figure 4).

The reduction in water yield was considerably lower with the driest year (55\% of long term rainfall) in all cases (Figure 4). Under drier conditions, evapotranspiration is largely under the control of soil water content, and so differences in vegetation cover and canopy conductance across catchments are likely to have less effect on evaporative fluxes and consequently on streamflow. A recent study by Zhou et al. (2013) concluded that the use of vegetation dynamics from remotely sensed data led to improvements in post-fire streamflow prediction in wet catchments, but not in dry catchments. This can result in little or no statistically significant change in post-fire streamflow, even when large areas of a catchment are affected by fire (Bart and Hope, 2010).

In the five years preceding the wildfire of 2009 , rainfall averaged about $77 \%$ of the long term average. We interpolated from our simulations of post-fire streamflow with rainfall between $55 \%$ and $84 \%$ to estimate the expected immediate increase in streamflow. For the O'Shannassy catchment, where the impact of the fire on long term streamflow is predicted to be greatest, the estimated immediate post-fire annual increase in streamflow (with $77 \%$ rainfall) was approximately $160 \mathrm{~mm}$. The $95 \%$ prediction interval for the observed data for the O'Shannassy catchment was calculated to be approximately $240 \mathrm{~mm}_{\text {year }}{ }^{-1}$, and so the estimated impact of post-fire streamflow increase is unlikely to be detected. For the Wallaby Creek catchment, the estimated immediate post-fire annual increase in streamflow (with 77\% rainfall) was approximately $120 \mathrm{~mm}$. With a $95 \%$ prediction interval of approximately $210 \mathrm{~mm}$ year $^{-1}$, the estimated impact of post-fire streamflow increase as estimated above may also be difficult to detect from observations. This highlights the use of modelling techniques to estimate the magnitude of potential changes that may not be detected in observations due to the inherent variability of streamflow. The chance of detecting an increase in post-fire streamflow after 2009 are consistent with early observations of streamflow from the Maroondah and O'Shannassy catchments by Tan et al. (2011). Using a runoff coefficient approach to compare rain and storm events before and after the 2009 wildfire, Tan et al. (2011) found no clear evidence of an increase in post-fire runoff in the first 16 months after the fire.

Our results agree with the experimental findings of Bart and Hope (2010), who found that post-fire streamflow in catchments with rainfall between $500-800 \mathrm{~mm}_{\text {year }}{ }^{-1}$ varied, and depended most on post-fire wetness conditions. Given the general correlation with rainfall, soil water content is the likely determinant of streamflow response to land-cover change.

In another study investigating two severely burnt catchments in 1965 in south-eastern New South Wales (south-eastern Australia) with similar rainfall as the O'Shannassy catchment, Brown (1972) observed runoff to be higher than it otherwise would have been for four years after the fire, even with below average post-fire rainfall. Conditions leading up to this wildfire led to soil water that would have been above average. The observed increase by Brown (1972) in post-fire streamflow supports the importance of soil water content on the post-fire response.

In a study on a small forest catchment, Lane et al. (2006) suggest a lack of immediate post-fire increase in streamflow may have resulted from low soil water content after preceding dry weather. Similary, Webb and Jarrett (2013) suggested that a downward shift in rainfall in their study catchments may have masked any streamflow reductions in fire-affected catchments.

\section{CONCLUSIONS}

Catchment scale hydrologic models were developed to investigate effects of climate on long term post-fire streamflow is several Melbourne water supply catchments. Under conditions of low rainfall and low soil water content, an initial increase in post-fire streamflow due to reduced evapotranspiration and canopy cover may not occur, or be undetectable, because a substantial soil water deficit must first be removed before appreciable changes in streamflow will occur. In a similar way, the longer term decline in post-fire streamflow often observed in catchments dominated by ash-type eucalypt species may not occur or be detected. We conclude, therefore, that the likelihood of detecting changes in streamflow after severe wildfire is lower when under low rainfall conditions.

\section{ACKNOWLEDGMENTS}

This study was funded by Melbourne Water (MW) and by the then Victorian Department of Sustainability and Environment (DSE) Integrated Forest Ecosystem Research program. Rob Yurisich, Fereal Addicott and 
Feikema et al., Simulating the combined effects of climate and wildfire on streamflow

Abby Farmer (MW) provided valuable guidance throughout the study. We thank Ian Watson, Abby Farmer, Anya Jones-Gill and Rob Yurisich (MW) for providing daily precipitation, temperature, and streamflow data. The Bureau of Meteorology provided daily precipitation and temperature data.

\section{REFERENCES}

Bart, R. and Hope, A. (2010). Streamflow response to fire in large catchments of a Mediterranean-climate region using paired-catchment experiments. Journal of Hydrology, 388, 370-378.

Brown, J.A.H. (1972). Hydrologic effects of a bushfire in a catchment on south-eastern New South Wales. Journal of Hydrology, 15, 77-96.

Davis, S.H. (2000). Measurement of Soil Hydraulic Properties and Implications for Catchment Modelling. PhD Thesis, Dept of Civil Engineering, Monash University, Melbourne, Australia.

Department of Primary Industries and Department of Sustainability and Environment (2004). In: O’Brien, M. (Ed.), Corporate Geospatial Data Library Catalogue, 17th ed.

Feikema, P.M., Sherwin, C.B. and Lane, P.N.J. (2013). Influence of climate, fire severity and forest mortality on predictions of long term streamflow: potential effect of the 2009 wildfire on Melbourne's water supply catchments. Journal of Hydrology, 488, 1-16.

Kuczera, G.A. (1987). Prediction of water yield reductions following a bushfire in ash-mixed species eucalypt forest. Journal of Hydrology, 94, 215-236.

Lane, P.N.J., Sheridan, P.J. and Noske, P.J. (2006). Changes in sediment loads and discharge from small mountain catchments following wildfire in south eastern Australia. Journal of Hydrology, 331, $495-510$.

Peel, M.C., Watson, F.G.R., Vertessy, R.A., Lau, J.A., Watson, I.S., Sutton, M.W. and Rhodes, B.G. (2000). Predicting the Water Yield Impacts of Forest Disturbance in the Maroondah and Thomson Catchments Using the Macaque Model. Technical Report 00/14. The Cooperative Research Centre for Catchment Hydrology, Melbourne, Australia.

Tan, K.S., Flower, D.J.M. and Flowers, D.M. (2011). An Event Runoff Coefficient Approach for Assessing Changes in Short-term Catchment Runoff Following Bushfires. Proceedings of the 33rd Hydrology and Water Resources Symposium, Brisbane, Engineers Australia, p. 1522-1529.

Vertessy, R., Watson, F., O'Sullivan, S., Davis, S., Campbell, R., Benyon, R.. and Haydon, S. (1998). Predicting water yield from mountain ash forest catchments. In. Cooperative Research Centre for Catchment Hydrology, p. 38.

Vertessy, R.A., Watson, F.R. and O'Sullivan, S.K. (2001). Factors determining relations between stand age and catchment water balance in mountain ash forests. Forest Ecology and Management, 143, 13-26.

Watson F.G.R., Vertessy R.A. and Grayson R.B. (1999). Large-scale modelling of forest hydrological processes and their long-term effect on water yield. Hydrological Processes, 13, 689-700.

Watson, F., Vertessy, R., McMahon, T., Rhodes, B. and Watson, (2001). Improved methods to assess water yield changes from paired-catchment studies: application to the Maroondah catchments. Forest Ecology and Management, 143, 189-204.

Watson, F.G.R. (1999). Large scale, long term modelling of the effects of land cover change on forest water yield. PhD thesis, Department of Civil and Environmental Engineering, The University of Melbourne, Australia.

Webb, A.A. and. Jarrett, B.W. (2013). Hydrological response to wildfire, integrated logging and dry mixed species eucalypt forest regeneration: The Yambulla experiment. Forest Ecology and Management, 306, $107-117$

Zhou, Y., Zhang, Y., Vaze, J., Lane, P. and Xu, S. (2013). Improving runoff estimates using remote sensing vegetation data for bushfire impacted catchments. Agricultural and Forest Meteorology, http://dx.doi.org/10.1016/j.agrformet.2013.04.018. 